\title{
Experimental studies of fiber concrete creep
}

\author{
Irina Korneeva ${ }^{1, *}$, Stepan Neutov $^{1}$, and Mykola Suriyaninov ${ }^{1}$ \\ ${ }^{1}$ Odessa State Academy of Civil Engineering and Architecture, Structural Mechanics Department, \\ Didrikson str., 4, Odessa 65029, Ukraine
}

\begin{abstract}
The results of two-stage experimental studies of the strength and deformation characteristics of fibrous concrete reinforced with steel fiber. In the experiments we used steel fiber with bent ends, which practically does not form "hedgehogs", which allows to achieve an even distribution of the fiber by volume. At the first stage, the cube and prismatic strength, deformability at central compression, a number of special characteristics are determined: water absorption, frost resistance, abrasion; the optimal percentage of fiber reinforcement and the maximum size of the coarse aggregate fraction were selected. Fiber reinforcement led to an increase in the strength of concrete at compression by 1,35 times and an increase in the tensile strength at bending by 3,4 times. At the second stage, the creep of fibrous concrete and plain concrete of similar composition at different stress levels was researched. Creep curves are plotted. It is shown that the use of fiber reinforcement leads to a decrease in creep strain by 21 to 30 percent, depending on the stress level.
\end{abstract}

\section{Introduction}

In recent decades, the distinctive feature of the development of industrial production is the use of new materials, and in particular, composites. In construction, this material is fiber concrete. The appeal of fiber concrete is due to the fact that it has higher strength and deformation characteristics than ordinary concrete. This makes it possible to effectively use fiber concrete in structures that are used in difficult conditions - bridges, tunnels, airfields, offshore structures, etc.

The use of fiber-reinforced concrete in fiber-reinforced concrete structures requires knowledge of a wide range of its physic-mechanical characteristics obtained as a result of laboratory tests. Many specialists were engaged in such studies [1-3], however, analysis of data on the effect of disperse (fibrous) reinforcement on the strength properties of fiberreinforced concrete indicates their ambiguity. This difference can be explained by a number of objective reasons - the composition of the matrix, the type of fiber and the percentage of fiber reinforcement, the size of the samples, the conditions of the experiment, etc.

Nevertheless, the strength characteristics of fiber-reinforced concrete are now sufficiently well studied both theoretically and experimentally $[4,5]$. The dependence of the strength on such parameters as the percentage of reinforcement, the length, diameter and shape of the fibers was studied, the effect of the fiber orientation, the strength of the matrix

* Corresponding author: sng@ogasa.org.ua 
material, and the composition of the concrete was taken into account. On the basis of the work done, regulatory documents have been created for the calculation of steel fiberreinforced concrete structures [6-8].

Deformation characteristics, especially creep and shrinkage under long-term load action, have been studied much worse.

\section{Results}

In order to fill the existing gap, we conducted experimental studies, during which we studied the work of fiber concrete with a long-term load action.

The test program provides for two phases. At the first stage, cubical and prismatic strength, deformability under central compression, a number of special characteristics (water absorption, frost resistance, etc.) were determined. At the same time, the percentage of fibrous reinforcement varied, which was $0,5 \%, 1,0 \%$ and $1,5 \%$, and the maximum size of a large aggregate (granite crushed stone) - with the size of the fraction $\leq 10 \mathrm{~mm}$ in the first series of tests and $\leq 20 \mathrm{~mm}$ in the second.

In the experiments we used steel fiber with bent ends (Fig. 1), produced by PJSC "PA" Stalkanat-Silur" in accordance with the European standard EN 14889-1: 2006 [9].

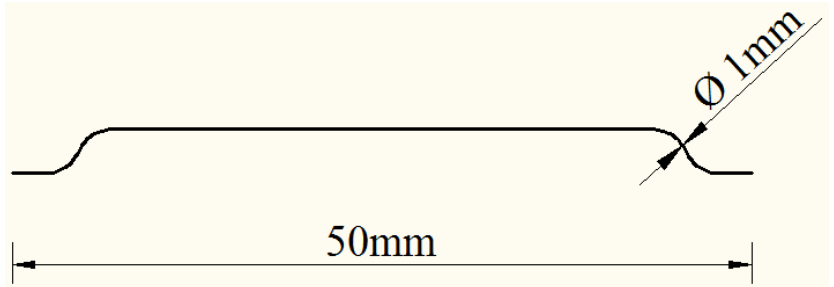

Fig. 1. Fiber with bent ends.

The fiber is made of wire with a temporary resistance of $1150 \mathrm{MPa}$ (1 class), $1335 \mathrm{MPa}$ (2 class) and $1550 \mathrm{MPa}$ (Grade 3).

World experience of practical application indicates that the fiber with folded ends practically does not form "hedgehogs", which allows to achieve its uniform distribution by volume.

In the studies carried out, class 2 fibers with a diameter of $1 \mathrm{~mm}$ were used. The main characteristics of the fiber are given in Table 1.

Table 1. Main characteristics of fiber before.

\begin{tabular}{|c|c|c|c|c|c|}
\hline Type & $\begin{array}{c}\text { Length, } \\
\mathrm{mm}\end{array}$ & $\begin{array}{c}\text { Diameter, } \\
\mathrm{mm}\end{array}$ & $\sigma_{u}, \mathrm{MPa}$ & $E, \mathrm{MPa}$ & $\mu$ \\
\hline HE50 & 50 & 1.0 & 1335 & 200000 & 0.3 \\
\hline
\end{tabular}

For the production of the matrix, cement 400 was used, washed river sand. The watercement ratio was 0.449 .

In order to compare the properties of concrete and steel-fiber-concrete, all types of tests were carried out on samples made of both materials.

Table 2 shows the parameters of the samples used and the types of tests performed.

The conducted studies showed that, in comparison with ordinary concrete, the structure of fiber concrete is characterized by a smaller number of large pores and a higher uniformity. As is known, contact zones of the interphase layer with improved mechanical properties are formed in conventional concrete. In fiber-reinforced concrete these zones 
were 5 to 6 times larger, and their total number increased. Obviously, this leads to an increase in the physical and mechanical characteristics of the material as a whole. In addition, the steel fiber arbitrarily oriented in the sample redistributes the gradients of stresses arising under the load, resulting in a decrease in stress concentration.

Table 2. Samples and types of tests.

\begin{tabular}{|c|c|c|l|}
\hline $\begin{array}{c}\text { Type of } \\
\text { sample }\end{array}$ & Material & $\begin{array}{c}\text { Sizes, } \\
\mathrm{mm}\end{array}$ & \multicolumn{1}{c|}{ Determined characteristics } \\
\hline Cube & Concrete & $100 \times 100 \times 100$ & $\begin{array}{l}\text { Cubic strength, frost resistance, abrasion, water absorption, } \\
\text { stretching during splitting }\end{array}$ \\
\hline Prism & Concrete & $100 \times 100 \times 400$ & $\begin{array}{l}\text { Prismatic strength, Poisson's ratio, modulus of elasticity, } \\
\text { crack resistance in bending }\end{array}$ \\
\hline Cube & SFC & $100 \times 100 \times 100$ & $\begin{array}{l}\text { Cubic strength, frost resistance, abrasion, water absorption, } \\
\text { stretching during splitting }\end{array}$ \\
\hline Prism & SFC & $100 \times 100 \times 400$ & $\begin{array}{l}\text { Prismatic strength, Poisson's ratio, modulus of elasticity, } \\
\text { crack resistance in bending tensile strength in bending }\end{array}$ \\
\hline
\end{tabular}

The tests of cubes and prisms were carried out according to the standard procedure in accordance with the current recommendations. Before installing the prism in the universal test machine (press) or the stand (depending on the type of test), strain gauges were attached to its face, and one hour-type indicator with a fission value of $0.001 \mathrm{~mm}$ and a base of $250 \mathrm{~mm}$ was attached to it. The prisms were loaded with steps: first three steps were applied with load of $0.1 F_{\text {max }}$, next with load of $0.2 F_{\max }$ With an exposure at each stage of 5-8 minutes with a total test duration of at least 45 minutes. In the intervals between the loading stages using the Brunell tube, the cracking process was monitored on the prism surfaces. At a load equal to $0.85 F_{\max }$, the measuring instruments were dismantled and the prisms were brought to destruction. Thus, as a result of the tests, data were obtained that described only the ascending branch of the "strain-load" diagram.

The qualitative form of the "strain-load" diagram is shown in Fig.2.

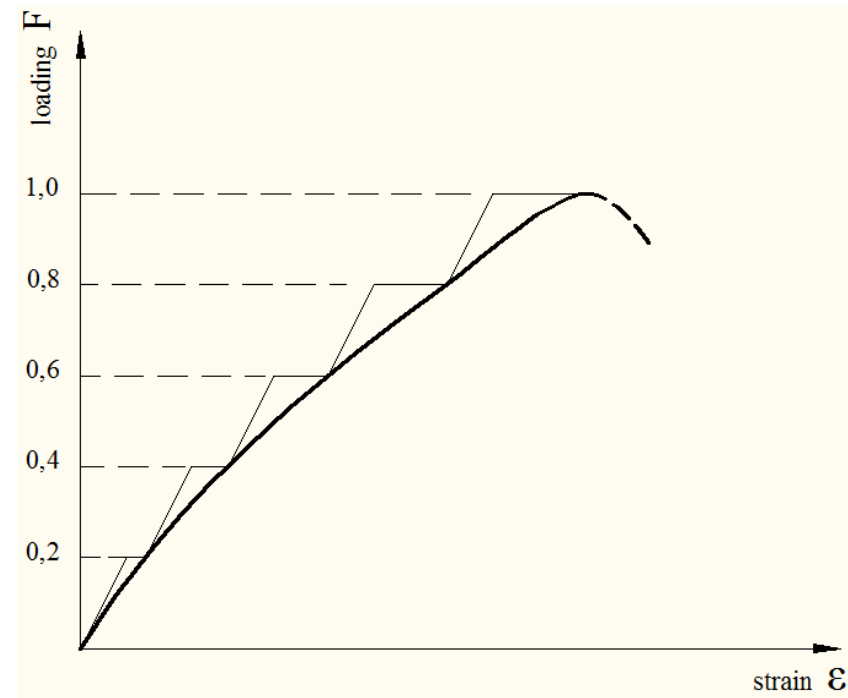

Fig. 2. "Strain-load" diagram. 
The destruction of the samples was preceded by the formation of cracks along the axis of action of the compressive load. At the same time, the destruction of samples with $0.5 \%$ fibrous reinforcement, as well as of ordinary concrete, was clearly frail and accompanied by their complete separation into separate blocks. At $1.0 \%$ and $1.5 \%$ fibrous reinforcement of frail fracture and sample separation were not observed.

Based on the test results, complete longitudinal strain diagrams $\sigma-\varepsilon$ for $0.5 \%, 1.0 \%$ and $1.5 \%$ fiber reinforcement for two matrix variants are formulated.

The results of the first stage of the tests showed that the optimal characteristics of the fiber concrete mixture is a matrix with a large aggregate of the fraction $\mathrm{mm}$ at $1.0 \%$ fiber reinforcement. Therefore, to study the creep in the second stage of the tests, there were made samples-prisms of 100x100x400 mm in size from fiber concrete and ordinary concrete of the same composition (Fig. 3), which were tested on special test benches designed to study creep (Fig. 4).

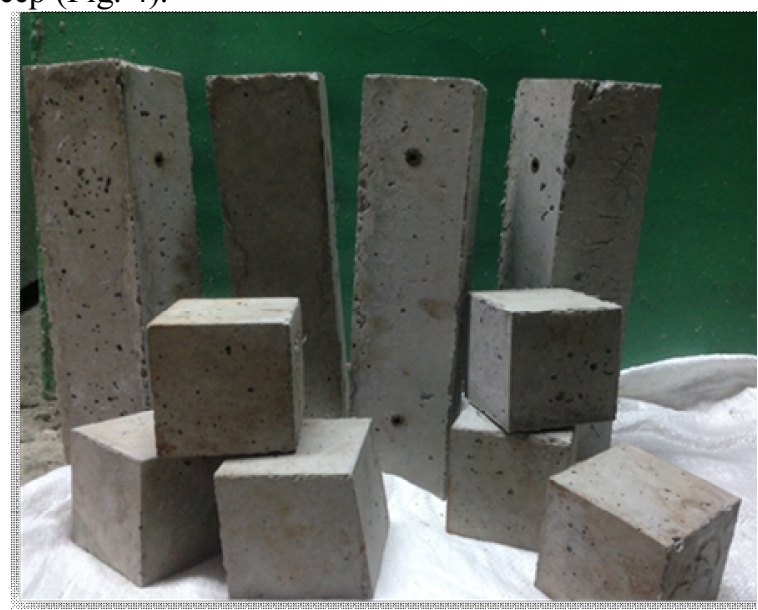

Fig. 3. Samples for testing.

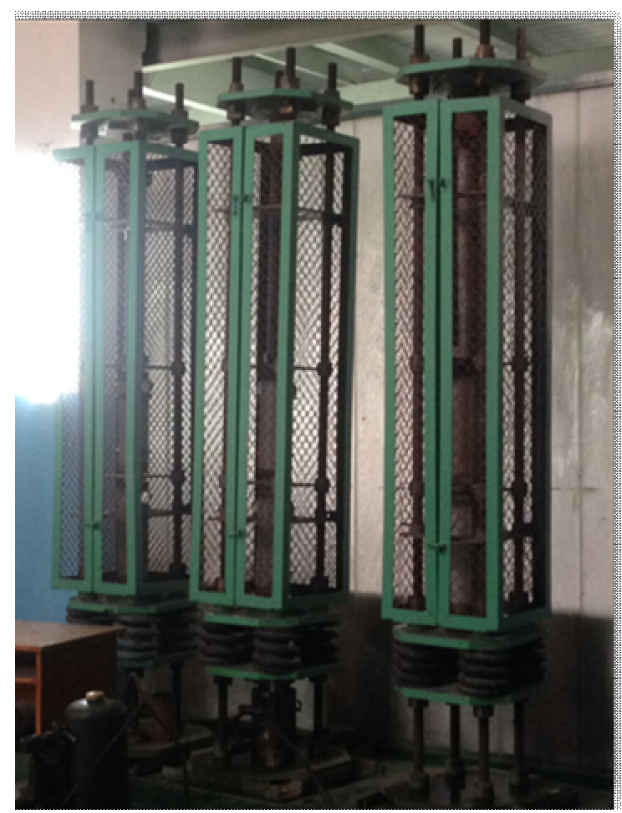

Fig. 4. Test benches for creep and long-term strength testing. 
Before the beginning of the main tests, a number of auxiliary (preliminary) experiments were carried out, the results of which determined the levels of prolonged loading $-0.3 ; 0.4$; $0.5 ; 0.67$ and 0.8 from the prismatic strength. During long tests, after reaching a predetermined loading level, the load was fixed, and with the help of a spring cassette and a jack was maintained throughout the experiment (180 days).

In order to compare the results of experimental studies on each stand, two prisms were located in one power row: one of ordinary concrete, and the second of fiber concrete. This loading scheme makes it possible to apply the same load level to the two samples and maintain it throughout the experiment.

The creep curves formulated by mathematical processing of the test results are shown in Fig. 5.

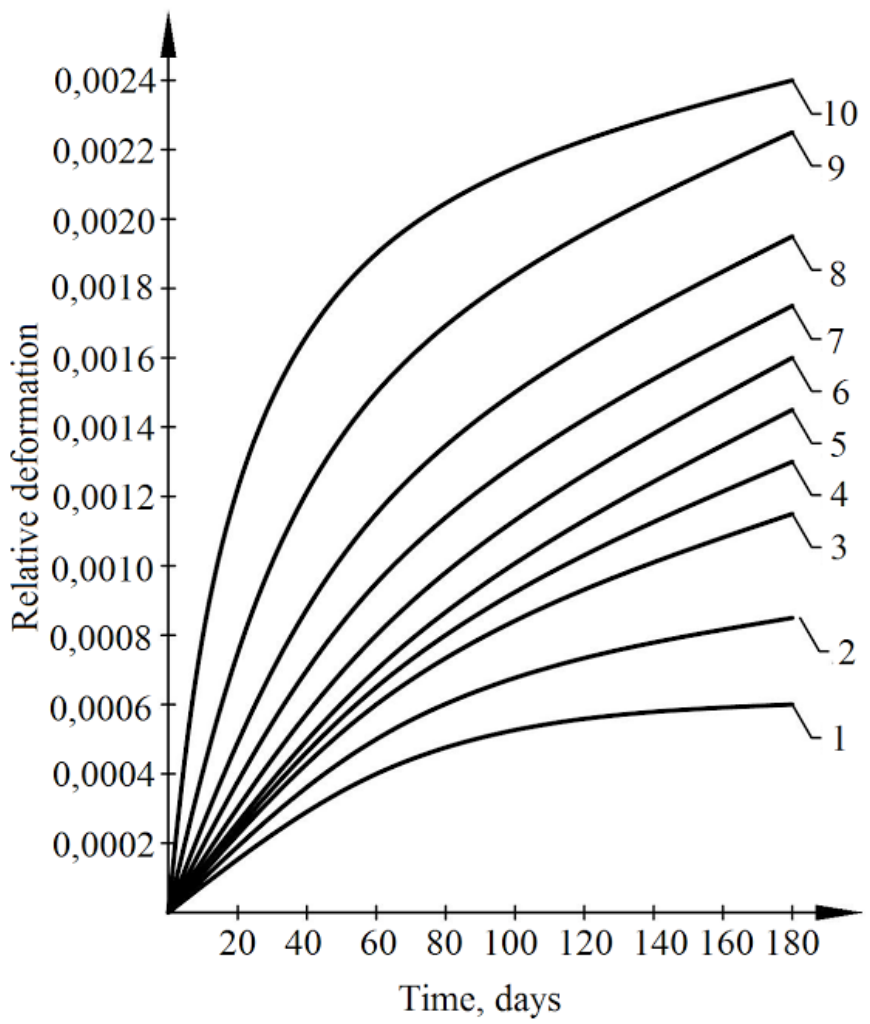

Fig. 5. Creep curves: 1, 3, 5, 7, 9 - fiber concrete; $2,4,6,8,10$ - ordinary concrete at $0.3 R ; 0.4 R$; $0.5 R ; 0.67 R ; 0.8 R$.

\section{Conclusions}

The destruction of samples from $0.5 \%$ fiber reinforcement is fragile, which is not observed at $1.0 \%$ and $1.5 \%$ fiber reinforcement. Optimum characteristics of the fiber-reinforced concrete mixture is a matrix with a large aggregate of the fraction $\leq 10 \mathrm{~mm}$ at $1.0 \%$ fiber reinforcement. Fiber reinforcement led to an increase in the strength of concrete for compression by 1.35 times and an increase in the tensile strength by bending by 3.4 times. In this case, the creep strains decrease by 21-30 percent, depending on the stress level. 


\section{References}

1. V.B. Aronchik, Thesis for Doctor of Philosophy. (Riga, 1982)

2. F.N. Rabinovich, Composites based on dispersed reinforced concrete. Issues of theory and design, technology (Moscow, 2006)

3. K.V. Talantova, Polzunovsky vestnik, 1, 194-199 (2011)

4. N.P. Bleschik, Problems of modern concrete and reinforced concrete: materials of the III International Symposium, 2, 80-113 (2011)

5. A.M. Bragov, Vestnik of Lobachevsky University of Nizhni Novgorod, 4, 123-129 (2001)

6. EN 14845-2:2006 Test methods for fibers in concrete. Effect on concrete, Brussels (2006)

7. SP 52-104-2006 Steel-fiber-concrete structures, Moscow (2006)

8. DSTU-N-B V.2.6-78:2009 Guidelines for the design and manufacture of steel-fiberconcrete structures, Kiev (2009)

9. BS EN 14889-1:2006 Fibres for concrete. Steel fibres. Definitions, specifications and conformity, London (2006) 